\title{
THE VIRTUE OF RUNNING A MARATHON Simone Gozzano
}

Running a marathon is not solely a personal achievement; rather it sets an example. Because of the nature of this example, it constitutes an achievement that deserves our praise (contrary to what has recently been argued in this Journal).

Running a marathon is quite an achievement. This sort of achievement, however, doesn't deserve much praise, because, ultimately, it is a self-regarding virtue. This is the thesis defended by Sarajlic (2018) in a recent issue of Think. In Sarajlic's view, the ability to run a marathon is crucially based on the willpower of the people that run it, and willpower as such is a virtue. However, the practice of such a virtue doesn't affect anyone else beyond the agent. So, it is a self-regarding virtue, and self-regarding virtues don't deserve much praise. It is my contention that Sarajlic has missed an important role that the practice of sports plays in general, and that marathons play, in particular. A role that, if well understood, should be praised, or so I will argue in this article.

As Sarajlic recognizes, running a marathon 'is not for the weak'. It takes considerable stamina and determination to run continuously for more than $42 \mathrm{~km}$ because your body, after enduring stress for some $35 \mathrm{~km}$, runs out of basic nutrients, such as glycogen, that allow your body to work properly. It is at that moment that willpower kicks in, even leading to physiological changes that allow the runner to get the job done. But why should we praise these runners?

It is virtues and virtuous actions which deserve praise if performed, and blame if not pursued. Sarajlic endorses Kant's view of virtue, according to which an action is 
virtuous if it can be established as a rule of conduct for everyone. So, a virtue is that kind of action that affects everyone in a positive way. A virtue, then, should not just be good for you personally, but should have those features that make it good for human beings in general and as such. In general, because everyone pursuing the virtue will not only benefit from this pursuit themselves but, more importantly, they will also provide benefits for everyone else. It is a virtue, as such, because humanity, by its nature, is to be identified as that natural kind that is properly characterized by specific conducts, and practising virtues is one of these conducts. For instance, generosity rewards the agent and the patient, thus qualifying for generality, and is good by its very nature, thus qualifying in terms of its intrinsic humanity as such. However, running a marathon doesn't stand up to these tests to qualify as a virtue because, in Sarajlic's eyes, it is merely selfregarding.

Is the virtue of running a marathon self-regarding? Historically, Pheidippides ran from the village of Marathon to Athens, to inform the Athenians that the Persians had been defeated and the Athenians should not surrender. Shortly after his announcement, he collapsed and died. The very origins of the marathon, then, tell the story of a soldier who obeyed an order, and obeyed it at the cost of his life. That surely was not a self-regarding act. To be sure, today, running a marathon is an entirely different matter. However, I believe that even today, running a marathon betrays its origin. What is the significance of the marathon nowadays? It sets an example. And this example is good for all.

Let me consider the professional runners first, those who run, whatever distance, as part of their professional life. We admire sport champions, because of their determination and ability. In the case of professional runners, however, the amount of effort they exert signifies something special for us: marathoners devote themselves to their sport far beyond the limits of other runners. For instance, an 
Olympic medallist and world record holder such as Mo Farah can, in the same Olympics, run both the $5 \mathrm{~km}$ and $10 \mathrm{~km}$ races. However, no one runs a marathon and another race, in the same competition. Clearly, there are tactical reasons not to run a marathon as well as another race. There could be, in general, reasons not to practise two or more sports or activities one after the other, since one may undermine the performance of the other. It is also true that there are sports that combine long-distance running with other activities, such as the triathlon. But in the case of the marathon, training and preparation require that one trains and prepares exclusively for that marathon because the stress and stamina required are so great that combining this training with other activities would undermine performance. That is, even though some sports can be practised together with positive results while practising others together has negative effects, marathons combine negatively with all other sports. So, we admire the willpower of marathoners because it represents the ultimate level of determination; the effort it takes to run a marathon cannot be compared to any other race, even running more than one race in the same competition. Admiration is not to be identified with passive participation: even if few people will watch an entire marathon on TV, while most enjoy watching the $100 \mathrm{~m}$, a downhill ski run, or whatnot, the level of determination required to run a marathon is considered the highest.

But perhaps non-professional runners are those who deserve the highest praise. Training for a marathon takes a lot of time. Sarajlic notes that one could have used this time for other goals, such as committing oneself to some humanitarian cause or the like. But, without doubting the value of humanitarian efforts, what value should we confer on running a marathon? As I said, I think that the main moral value of this activity is that it sets an example. So, what is the value of the example of running a marathon in the case of a non-professional runner? 
We can consider two main reasons why setting an example in this case is a virtue. First, non-professional runners show other people that such an achievement is feasible, thus helping them to discover their own personal capacity. By running and training, non-professional runners are encouraging others, not necessarily in an explicit manner, but still encouraging others to aim for the same level of achievement. Since the people who finish a marathon are like us with respect to their physical and mental capacities, we can imagine ourselves accomplishing the same goals. This kind of encouragement, moreover, has many positive dimensions: encouraging one to discover how to overcome one's own limits, to reap health benefits, to join with others in training and races, and to make new friends and acquaintances. These benefits can affect the person one is and becomes.

Second, by following the path of marathoners, people become conscious of the strength and degree of their willpower, a willpower they can learn to apply and practise for other purposes or in other disciplines and activities. As we said, it takes a lot of willpower to finish a marathon; but the mental and moral closeness of the people who do finish a marathon can instil in each of us the (justified) conviction that we may have the same degree of willpower. A degree that perhaps is somehow buried by daily routine.

As I said at the beginning, Sarajlic, following Taylor and Wolfram (1968), divides virtues into those that are selfregarding and other-regarding. Both the mentioned aspects of setting an example, I think, constitute values which are other-regarding. This should not come as a surprise. The reason is that setting an example is intrinsically otherregarding because, in order to be an example one must be an example to someone else. ${ }^{1}$ So, in this sense setting an example by running a marathon meets the challenge raised by Sarajlic. But what distinguishes the case of the marathon from many other potential cases in which someone sets an example? And, more to the point, even if setting an example is a virtue, if running a marathon is not in itself a 
value, why is setting an example good in this case? We said that the main benefits of the example set by running a marathon are that it encourages other people to foster and develop their own capacity and willpower. Fostering these characteristics in one's own person, in the case at hand, brings with it many general positive effects. It helps to reduce heart disease in the population, to reduce pollution (in many cities, many people walk or run to and from work instead of taking the car), to raise our self-esteem as we see we can increase our willpower. These are indirect benefits, to be sure. But we blame indirect damages, such as driving a car, for polluting the world. So, if we blame indirect damages, why not praise indirect benefits?

Sarajlic somehow considers this when he mentions the case of kale: even if one is disgusted by this vegetable, one may force oneself to eat it because of its health benefits, and even participate in a kale-eating competition. Nevertheless, eating kale still wouldn't be virtuous because beyond being self-regarding it is not a value in itself: borrowing from Kant, kale-eating wouldn't be categorically but only hypothetically valuable. This case can be challenged as well: eating healthy food is good in itself, because it is an act of self-care, and such acts foster capacity and willpower; acts of self-care bring about those indirect benefits l've already mentioned. As in the case of the marathon, the exercise of the act in itself is self-regarding but the value of the act is other-regarding, because it has an intrinsic value - setting an example of self-care - with indirect benefits.

Finally, it is noteworthy that the example set is an example of success. As Sarajlic himself informs us, the amount of people now running a marathon, or training for one, is steadily increasing. So, the previously mentioned benefits are now having a general impact on society.

A final note on Kant's maxims. To behave as if we are establishing universal maxims is to act as if we were setting a general example, one that should be taken as a norm. That is, to set an example implies having the 
intention to act for everyone's sake. If this is correct, the importance of behaving in such a way as to set an example accords with Kant's general principles of ethics. Thus, running a marathon is the virtue of setting an example that if followed will confer many important benefits. So, next time you meet a friend or colleague bragging after a marathon, pat her or him on the back and compliment your buddy: 'Well done, my friend!'

Simone Gozzano is professor in Philosophy of Mind and Metaphysics in the Department of Humanities at the University of L'Aquila. simone.gozzano@cc.univaq.it Thanks to Andrea lacona.

\section{Note}

${ }^{1}$ It is somehow unclear if one can be an example to oneself. Perhaps, one can think that something like this is the case when one does something one was unsure of being capable of. But this is an elliptical way of considering the issue of being self-surprised.

\section{References}

Sarajlic, E. (2018) 'Is Running a Marathon a Virtue?', Think 17(48): 101-5.

Taylor, G. and Wolfram, S. (1968) 'The Self-Regarding and Other-Regarding Virtues', The Philosophical Quarterly 18: 238-48. 